Type: Education paper

Section: Spectroscopy

\title{
Low-Cost Spectrometer for Educational Applications using Mobile Devices
}

\section{Espectrómetro de bajo costo para aplicaciones educativas usando dispositivos móviles}

\author{
Tatiana C. Muñoz Hernandez ${ }^{1 *}$, Esteban Gonzalez-Valencia ${ }^{1}$, Pedro Torres ${ }^{1}$, Diego Luis \\ Aristizábal Ramírez ${ }^{1}$ \\ 1. Escuela de Física, Universidad Nacional de Colombia, Sede Medellín, Medellín, Colombia \\ (*) E-mail: tcmunoz@unal.edu.co
}

\author{
Received 01/12/2016 Accepted: 03/07/2017
}

DOI: $10.7149 /$ OPA.50.3.49035

\begin{abstract}
:
In this work, we report the development of a low-cost attachment to a commercial cell phone that transforms the phone into a visible-light spectrometer for educational applications. The emission of a visible light source is readily detected and characterized by using the phone camera and a freeware application for Android mobile devices, PhysicsSensor Mobile Edition. The spectrometer has a $350 \mathrm{~nm}$ bandwidth with a spectral resolution of $5 \mathrm{~nm}$, which can be achieved through the calibration module that takes as reference the central wavelengths of a couple of LEDs whose emissions are blue and red. We demonstrate the functionality of the system by analyzing the emission spectrum of a sodium flame, a commercial sodium lamp and a commercial mercury lamp. We envision the devices to have immediate relevance in the educational field.
\end{abstract}

Key words: Education; Spectrometry; Spectroscope, Spectrometer.

\section{RESUMEN:}

En este trabajo se presenta el desarrollo de un dispositivo de bajo costo para un teléfono celular comercial que transforma dicho dispositivo móvil en un espectrómetro de luz visible para aplicaciones educativas. La emisión de una fuente de luz visible puede ser fácilmente capturada y caracterizada usando la cámara del teléfono y la aplicación de uso gratuito (freeware) para dispositivos móviles Android PhysicsSensor Mobile Edition. El espectrómetro tiene un ancho de banda de $350 \mathrm{~nm}$ con una resolución espectral de $5 \mathrm{~nm}$, que se obtiene a través del módulo de calibración, el cual toma como referencia las longitudes de onda centrales de dos LEDs cuyas emisiones son de color azul y rojo. Se demuestra la funcionalidad del sistema mediante el análisis del espectro de emisión de una llama de sodio, una lámpara de sodio comercial y una lámpara de mercurio comercial. Consideramos que éste desarrollo tiene relevancia inmediata en el campo educativo.

Palabras clave: Educación; Espectrometría; Espectroscopia; Espectrómetro.

\section{REFERENCES AND LINKS / REFERENCIAS Y ENLACES}

[1] G. Óli Sölvason, J. Timothy Foley, "Low-cost spectrometer for Icelandic chemistry education”, Procedia CIRP 34, 156-161 (2015). https://doi.org/10.1016/i.procir.2015.07.072

[2] O. Ormachea, O. Urquidi, J. Cisneros, "Development of a diffraction spectrometer and its control program using commercial, low-cost elements," REVISTA CUBANA DE FÍSICA, Vol. 30, No. 2 (2013). 
[3] E. Montoya Rossi, Ó. Baltuano Elías, A. Arbildo López, "Espectrómetro para radiación visible hecho en casa, de bajo costo y altas prestaciones," Rev. Soc. Quím. Perú, Vol.79, No.1, 80-91 (2013).

[4] D. Montiel, M. Ballinas y M. Jiménez, "Espectrómetro," Revista de la Sociedad Química del Perú, 79 (1) (2013).

[5] John G. Kassakian, Bruce D. Wedlock, "A low-cost spectrometer for instructional purposes", IEEE Transactions on Education, Vol. E-11, No. 4, 229-231(1968). https://doi.org/10.1109/TE.1968.4320411

[6] M. Rodrigues, M. B. Marques, P. Simeão Carvalho, "How to Build a Low Cost Spectrometer with Tracker for Teaching Light Spectra", Physics Education, 51(1) (2016). https://doi.org/10.1088/0031-9120/51/1/014002

[7] A. Trindade, B. Falcão, L. F. N. D. Carramate,M. I. S. F. Marques, R. A. S. Ferreira, P. S. André, "Low-cost spectrograph based on a WebCam: a student project", International Journal of Electrical Engineering Education, Vol. 51, No. 1 (2014). https://doi.org/10.7227/IJEEE.51.1.1

[8] NATIONAL INSTRUMENTS, http://www.ni.com/

[9] E. Ballester, J.C. Castro-Palacio, L. Velázquez-Abad, M.H. Giménez, J.A. Monsoriu, L.M. Sánchez Ruiz, "Smart physics with smartphone sensors," IEEE Frontiers in Education Conference (FIE) Proceedings, (2014). https://doi.org/10.1109/FIE.2014.7044031

[10] L. Martinez, P. Garaizar, "Learning Physics down a slide: A set of experiments to measure reality through smartphone sensors," IEEE Global Engineering Education Conference (EDUCON), (2014).

[11] PhysicsSensor, http://ludifisica.medellin.unal.edu.co/

[12] PhysicsSensor Mobile Edition, http://ludifisica.medellin.unal.edu.co/index.php/mobile

[13] ARDUINO, https://www.arduino.cc/

[14] Escuela de Física de la Universidad Nacional de Colombia - Sede Medellín, "Hoja técnica del Espectroscopio,"

http://ludifisica.medellin.unal.edu.co/recursos/physicssensor/hardware/espectroscopio.pdf

[15] T. C. Muñoz Hernandez, E. Gonzalez Valencia, and D. L. Aristizabal Ramirez, "Emission spectra analysis using an inexpensive spectrometer and PhysicsSensor," Latin America Optics and Photonics Conference, (Optical Society of America, 2016), paper LW4D.5.

[16] Diffraction Grating sheet 500 lines per mm. https://www.edmundoptics.com/optics/gratings/holographic-diffraction-grating-film/

[17] D. Aristizábal, R. Restrepo, C. Ramírez, "Fundamentos de espectroscopia empleando PhysicsSensor,", Guía Maestría en enseñanza de las ciencias exactas y naturales, Universidad Nacional de ColombiaSede Medellín, (2012).

http://ludifisica.medellin.unal.edu.co/recursos/physicssensor/aplicaciones/fundamentos espectros copia_con_physicssensor.pdf

[18] HSB-BW Bright White Blended; MSDS No. 0020414; Havells Sylvania: Noida, India. http://www.sylvanialighting.com.au/pdf-binder/print?id=323

[19] SHP-T Basic Plus; MSDS No. 0020846; Havells Sylvania: Noida, India. http://www.sylvanialighting.com.au/pdf-binder/print?id=316

[20] R. A. Serway, C. J. Moses, C. A. Moyer, “Modern Physics”, Cengage Learning, (2004).

\section{Introduction}

Spectrometry is a technique highly used for determine the elemental composition of a sample by analyzing its emission spectrum [1]. It is a measurement technique that allows the decomposition of light into its different wavelengths, so it is widely used in the analysis of light sources in different professional and scientific areas [2-4]. 
The instruments used to carry out spectrometry practices in educational laboratories are often expensive [5-7]. They remain relatively specialized devices, making it difficult to access at secondary education level and even at the university level, thereby limiting the possibility of acquiring adequate equipment that allows each student to manipulate and to experience while performing different laboratory practices.

On the other hand, the last decades have been characterized by important changes in the way in which the Internet has influenced the society in many aspects. These include the way that people quickly access information and how this can generate positive or negative impacts according to how it is assimilated. This effect has been strengthened with the incorporation of the mobile devices (smartphones and tablets). The challenge consist in incorporate these technologies into teaching-learning environments to make this technology an ally for educational processes. Today, personal computers and mobile devices can be powerful tools to be used in data acquisition and processing, also as part of virtual instrumentation [8], in which a hardware-software technology is developed to be used in the simulation and measurement processes in natural science laboratories. Recently, the smartphones have been incorporated into a variety of devices used for physics teaching, making use of the different capacities that they possess $[9,10]$.

In this work, we present a hardware-software implementation of a low-cost spectrometer for measuring the emission spectra of different light sources thorough the application PhysicsSensor Mobile Edition for Android devices. We demonstrate that this spectrometer is a very cost-effective instrument for education laboratories with limited funds for equipment.

\section{PhysicsSensor Mobile Edition and Visible-light spectrometer fabrication}

PhysicsSensor [11] is a hardware-software platform for personal computers and mobile devices, designed by professors of the School of Physics at the National University of Colombia, with the purpose of incorporate the New Technologies of Information and Communication (NTIC) in the laboratories of physics, substantially improving the measures (low uncertainties and consequently low error rates) with a very low economic investment. In this case, the designed spectrometer reaches the goal of incorporate the NTIC in education by using mobile devices to perform physical measurements in basic physical laboratories.

\section{2.a. PhysicsSensor Mobile Edition}

PhysicsSensor Mobile Edition [12] is the version for Android mobile devices (recommended for use it in devices with an Android version of 4.4, Kit-Kat or higher). This is a freeware license software package, property of the National University of Colombia, which uses device sensors, sound card, camera, and a USB port for the experimental data acquisition and processing, making a smartphone in a powerful data logger. The PhysicsSensor Mobile Edition software package has the following applications: accelerometer (inertial and non-inertial), inclinometer, thermometer (ambient temperature), barometer, hygrometer, altimeter, luxmeter, gaussmeter, soundmeter, signal generator, spectrometer, linear regression, quadratic regression, videotracker and a virtual instrument to connect with external sensors coupled through Bluetooth using, for instance, the ARDUINO card [13], which enhances the platform to be used in research activities. In this work was used PhysicsSensor Mobile Edition version 5.6.

\section{2.b. Visible-light spectrometer}

The proposed spectrometer $[14,15]$ consists of the following modules:

- Light Admission Module: It consists of a tube with a slit of approximately $0.2 \mathrm{~mm}$ wide and $25 \mathrm{~mm}$ high. The slit determines the diffraction pattern shape of the analyzed light source.

- Diffraction Module: It is composed by a convergent lens of focal distance $f=14 \mathrm{~cm}$, and a 500 lines/mm diffraction grating slide [16]. The function of the lens is to form an image at infinity of the slit used in the Light Admission Module, in order to uniformly illuminate the diffraction grating, which is responsible for the decomposition of the wavelengths of the source.

- Calibration module: This module consists of two common 5 V high intensity LEDs (red and blue), two power supply batteries (CR2032) and one input diaphragm. The module takes as reference the wavelengths of the blue and red LEDs to make measurements in our implementation. In the event that the data sheets of the LEDs are not available, it is necessary to obtain this information using another light source. To do this, it is proposed to use the spectrum of a fluorescent lamp whose spectral lines are known [17]. These lamps are widely used in laboratories and are very affordable. 
In anticipation of this situation, our calibrator has a diaphragm that covers the LEDs, allowing the independent observation of the spectra, as will be shown later.

The coupling between the light admission module and the diffraction module constitute a spectroscope; see Figure 1 (left). The calibration module is attached to the end of spectroscope where the slit is located, taking care to place the LEDs in that position. The group of these three modules form the spectrometer; see Figure 1 (right).

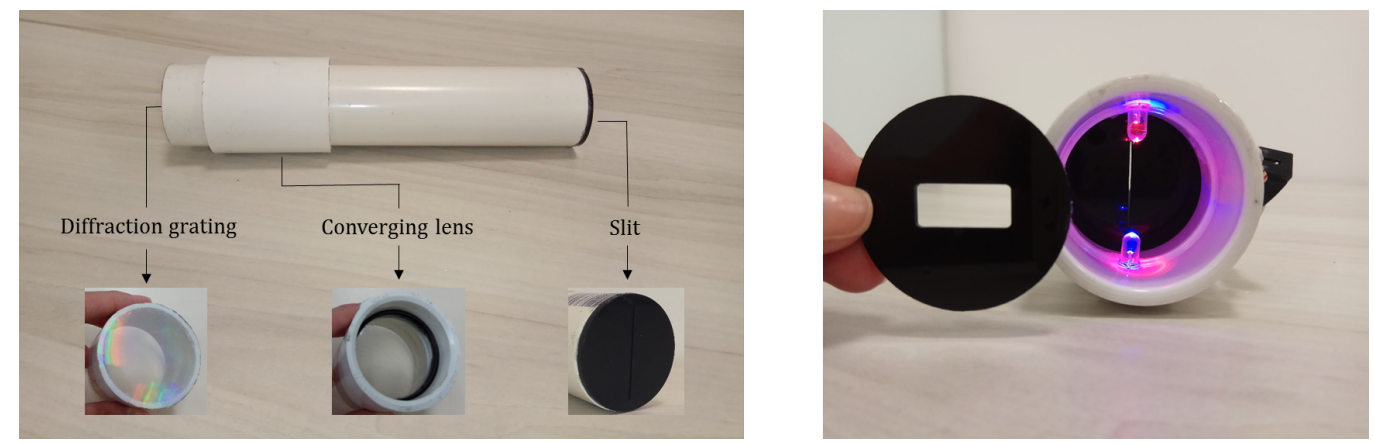

Fig.1. Spectroscope main components (left) and calibration module (right).

Once the spectrometer is fully assembled and the wavelengths of the LEDs of the calibration module are known, a spectral image of the visible light source under analysis can be taken by using the camera of the smartphone. The spectrometer components are summarized at the block diagram in Figure 2, left.
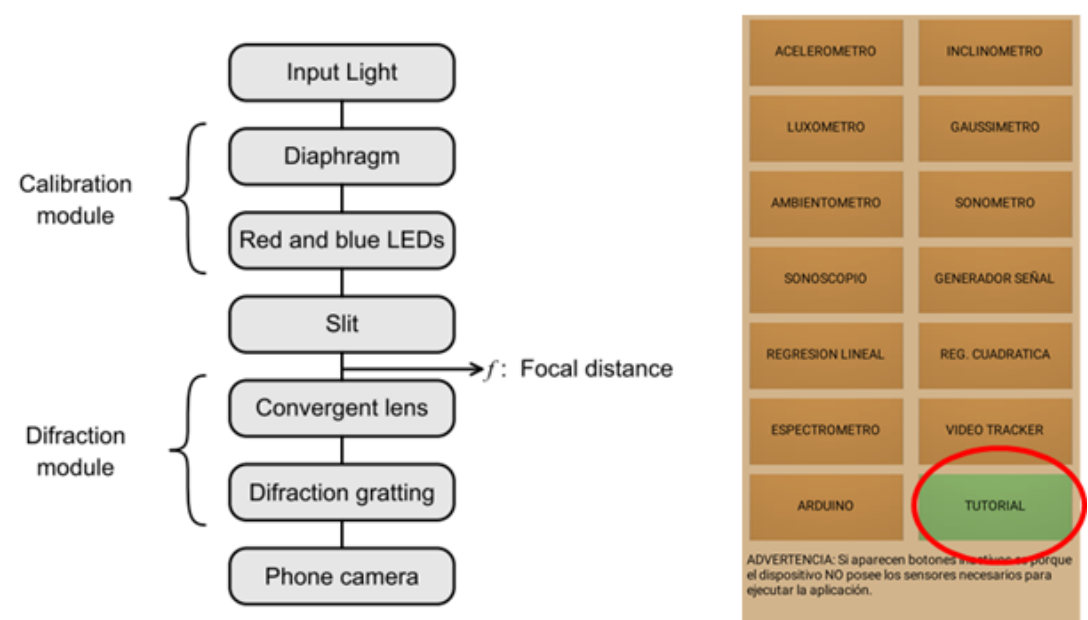

Fig.2. Spectrometer components (left), PhysicsSensor Mobile Edition interface (right).

In [14], a document in Spanish is available where each component of the spectrometer is shown in detail and it is explained how to construct this instrument step by step. Also, once the user installs the Android application (Figure 2, right), there is access to different tutorials where can be found laboratory guides, datasheet and videos to construct and use all the hardware instruments that comprised PhysicsSensors platform.

\section{2.c. Spectrum Image Capture}

In order to capture the image of the emission spectrum of the source of interest with the mobile device camera, the proposed spectrometer must be placed in front of the light source, so that both the spectra of the light source and the LEDs of the calibration module are observed. This picture will be similar to the one shown in Figure 3 (left), where the non-diffracted light of the slit is observed at the center and the first diffraction orders (+1 and -1) are on each side of it. To analyze the spectrum, it is necessary edit the picture either with PhysicsSensor Mobile Edition application or with another image editing software. This edited image must have the following characteristics:

- The picture must be cropped until only the emission spectrum of the source of interest and the spectrum of the calibration LEDs are observed (Figure 3, center). The selection of one of the two diffraction orders (+1 or -1$)$ will depend on the photograph quality. 
- All diffracted lines must be completely vertical.

- Spectral lines corresponding to the shorter wavelengths (violet and blue) should be located on the left side of the image (Figure 3 right).
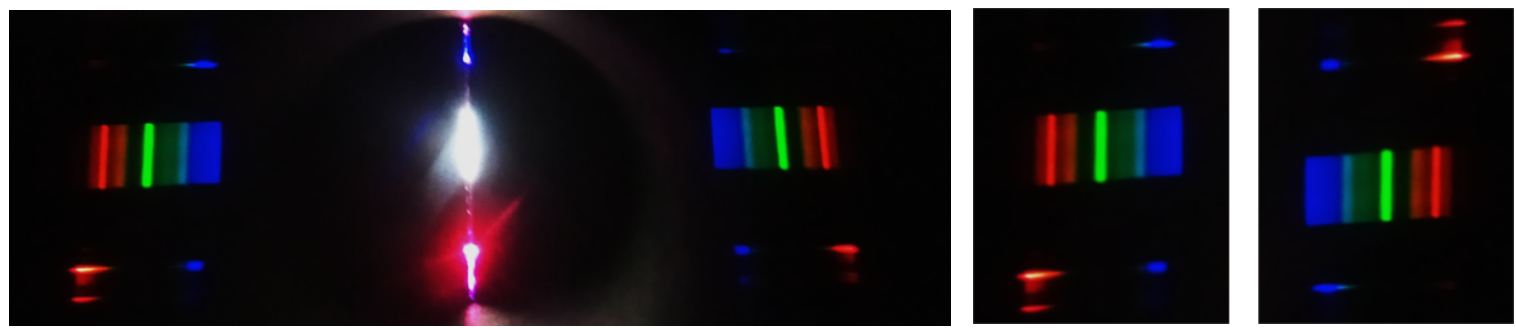

Fig. 2. First diffraction orders of a fluorescent lamp and the calibration module LEDs (left), and edited spectrum using PhysicsSensor Mobile Edition (center, right).

Importantly, the spectral lines seen in the photograph are determined by the rectangular shape of the slit. This geometry allows to improve the visualization of the different spectral bands to analyze, clearly avoiding the superposition of spectral lines. The minimum wide of the spectral lines will be limited by the diffraction effects, which in turn limits the spectrometer resolution. Also, the spectrometer resolution depends on the admission tube length and the number of lines/ $\mathrm{mm}$ of the diffraction grating (more lines/mm could be better, but it would move laterally the diffraction orders, making it difficult to take the picture with the smartphone camera). Although the camera properties (pixel size, sensor pixel density and optical quality) influences the system resolution, the camera quality of any current device is enough for this application, since the resolution limit is determined by the optical design. However, considering the simplicity and low cost of the proposed design, and the good obtained results - some of those reported in this work-, we assure that the resolution of the device is enough for educational purposes.

\section{2.d. Spectrometer application of the PhysicsSensor Mobile Edition}

The spectrometer application in PhysicsSensor Mobile Edition has two principal sections (Figure 4, left). The "Adquirir espectro" (acquire spectrum) section (Figure 4, center) allows to select the spectral region of interest as well as to edit the image, by selecting the region of interest (by pressing $\mathrm{X}+, \mathrm{X}-, \mathrm{Y}+$ and $\mathrm{Y}$ - buttoms) and to adjust it by rotations (by pressing $\mathrm{R}+$ and $\mathrm{R}$ - buttoms) and inversions (by pressing "Invertir espectro" buttom), according to 2 c section. The "Analizar espectro" (analyze spectrum) section (Figure 4, right) allows to select the previously edited spectrum (by pressing "ESPECTRO") and calibrate it (by pressing "CALIBRAR), for which, as stated, it uses the wavelengths of the diffracted light from the red and blue LEDs as reference. With this procedure, the wavelengths of interest from the emission spectrum of the light source under analysis are determined.
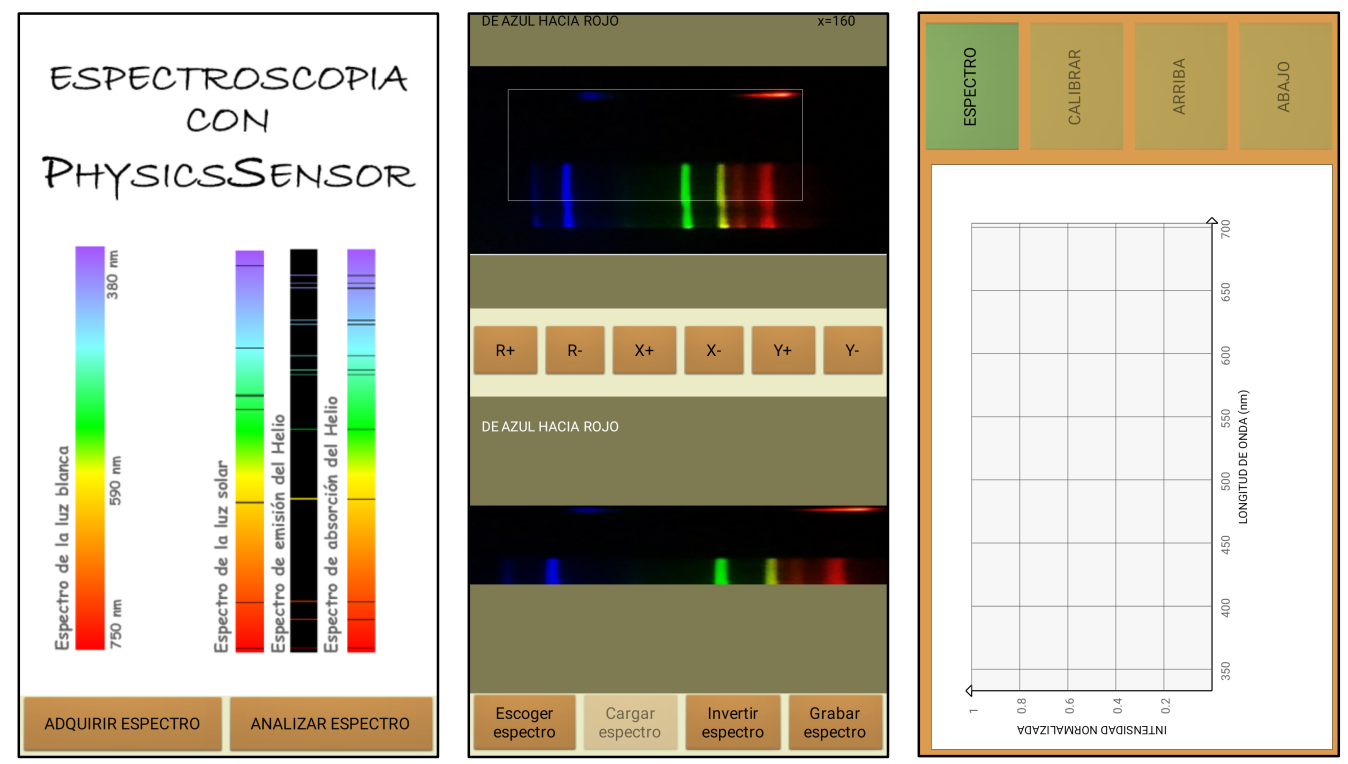

Fig.4. Interface of the spectrometer application software of PhysicsSensor Mobile Edition package. 


\section{2.e. Device applications}

Our spectrometer has a 350-nm bandwidth between 350-700 nm, with an approximate spectral resolution of $5 \mathrm{~nm}$, which can be achieved through the previously described calibration module. Figure 5 shows the images of emission spectra of a commercial mercury lamp (left), a commercial sodium lamp (center) and a sodium flame (right). In all these images, the spectrum of the source of interest, as well as the spectrum of red and blue reference LEDs can be observed. It should be noted that these images have already been edited taking into account the considerations given in section 2.c.
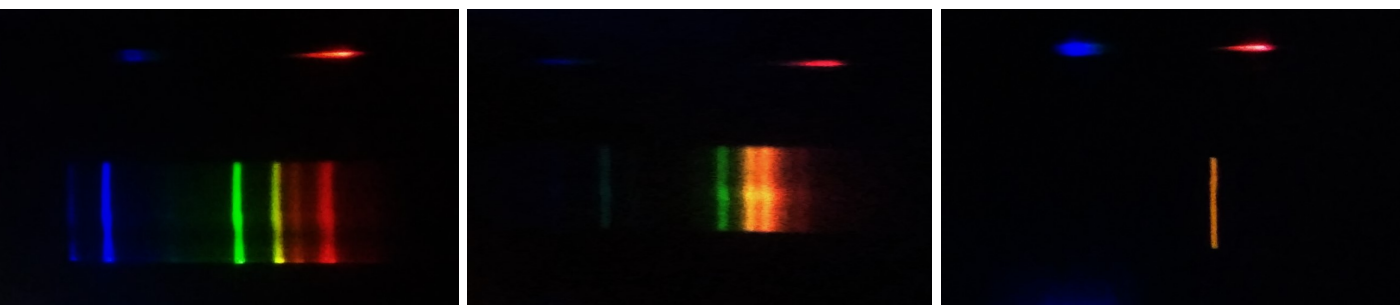

Fig.5. Emission spectrum of commercial mercury lamp (left), a commercial sodium lamp (center) and a sodium flame (right) obtained with the spectrometer proposed.

To verify the spectrometer operation, we analyze a commercial mercury lamp, whose spectrum was reported in its datasheet [18] (Figure 6, left). By analyzing the experimental spectrum with PhysicsSensor Mobile Edition (Figure 6, right), one can verify the presence of the most important emission bands. The wavelength measurements of each of these bands are listed in Table 1.
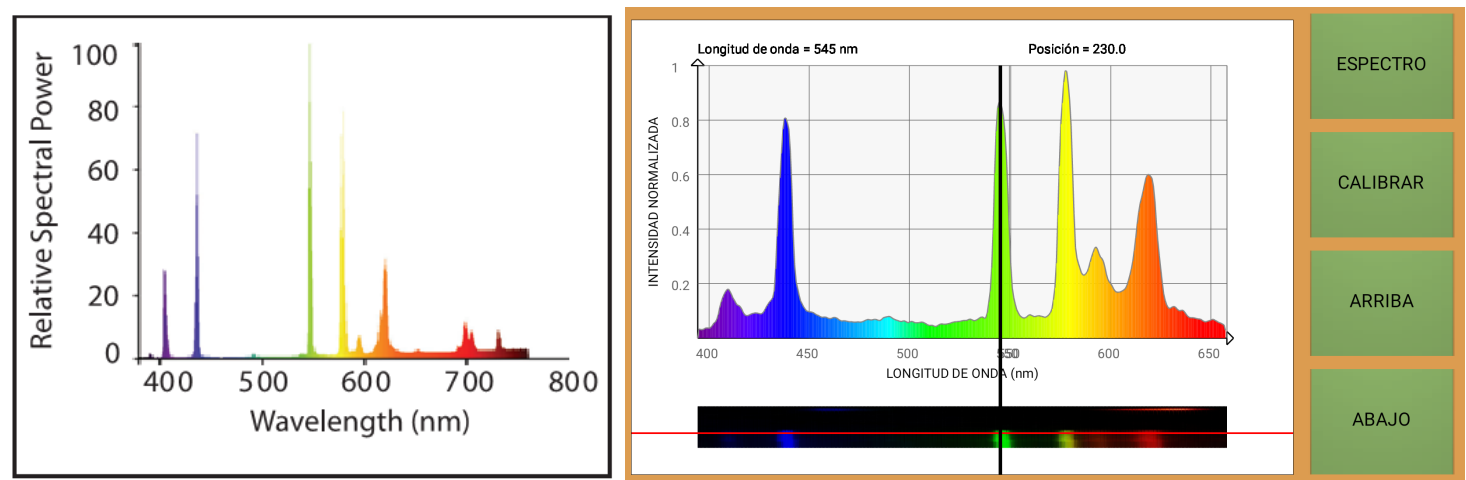

Fig.6. Datasheet (left) and spectrum analysis (right) of a commercial mercury lamp obtained with the Spectrum Analyzer application from PhysicsSensor Mobile Edition. As an example, a peak is observed at $545 \mathrm{~nm}$ (actual value $546 \mathrm{~nm}$, green, \% $\mathrm{E}=0.16$ ).

TABLE 1. Commercial mercury lamp analysis.

\begin{tabular}{|c|c|c|}
\hline \multicolumn{2}{|c|}{ Wavelength (nm) } & \multirow{2}{*}{ \% Error } \\
\hline \hline Datasheet [16] & $\begin{array}{c}\text { PhysicsSensors } \\
\text { Mobile Edition }\end{array}$ & \\
\hline 405 & 409 & 1.08 \\
435 & 436 & 0.12 \\
546 & 545 & 0.16 \\
579 & 578 & 0.03 \\
595 & 593 & 0.26 \\
620 & 619 & 0.12 \\
698 & - & - \\
705 & - & - \\
730 & - & - \\
\hline \hline
\end{tabular}


We also performed the same analysis of a commercial sodium lamp [19], as is verified from the spectrum in Figure 7. The wavelength measurements are shown in Table 2. Among them, the most intense band, yellow band $(595 \mathrm{~nm})$, which gives these lamps its characteristic color, with an error rate of $0.21 \%$.
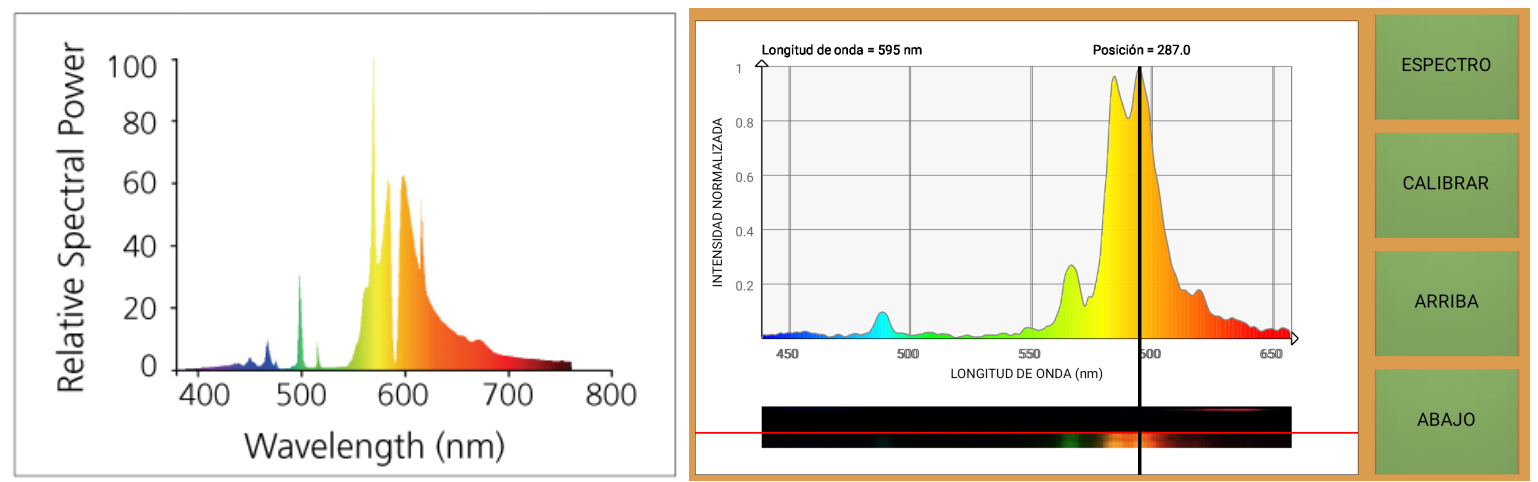

Fig.7. Datasheet (left) and spectrum analysis (right) of a commercial sodium lamp obtained with the Spectrum Analyzer application from PhysicsSensor Mobile Edition. As an example, a peak is observed at $595 \mathrm{~nm}$ (actual value $596 \mathrm{~nm}$, yellow, \%E=0.21).

TABLE 2. Commercial sodium lamp analysis.

\begin{tabular}{|c|c|c|}
\hline \hline \multicolumn{2}{|c|}{ Wavelength (nm) } & \multirow{2}{*}{ \% Error } \\
\hline \hline Datasheet [17] & $\begin{array}{c}\text { PhysicsSensors } \\
\text { Mobile Edition }\end{array}$ & \\
\hline 465 & - & - \\
497 & 490 & 1.34 \\
514 & - & - \\
571 & 567 & 0.63 \\
587 & 585 & 0.35 \\
596 & 595 & 0.21 \\
619 & 620 & 0.09 \\
776 & - & - \\
\hline \hline
\end{tabular}

Finally, an experimental measurement was made by exposing common salt $(\mathrm{NaCl})$ to a flame to verify that, according to the literature, sodium ( $\mathrm{Na}$ ) emits at two wavelengths, $588.995 \mathrm{~nm}$ and $589.592 \mathrm{~nm}$ [20]. Figure 8 shows the spectral analysis of the sodium flame under the PhysiscsSensor Mobile Edition software where is not possible to measure the sodium doublet because the spectrometer resolution and only an experimental emission peak is observed at $589 \mathrm{~nm}$, which contains the doublet energy, obtaining a maximum error rate of $0.1 \%$ (Table 3 ).

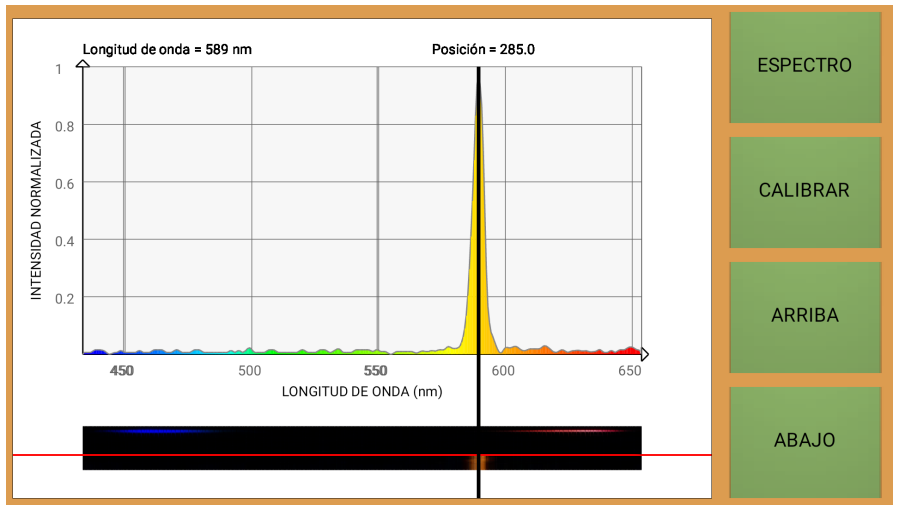

Fig.8. Spectrum analysis of a sodium flame obtained with the Spectrum Analyzer application from PhysicsSensor Mobile Edition. A peak is observed at $589 \mathrm{~nm}$ (actual value is approximately $589.6 \mathrm{~nm}$ ). 
TABLE 3. Sodium flame.

\begin{tabular}{|c|c|c|}
\hline \hline \multicolumn{2}{|c|}{ Wavelength (nm) } & \multirow{2}{*}{ \% Error } \\
\hline \hline Datasheet [18] & $\begin{array}{c}\text { PhysicsSensors } \\
\text { Mobile Edition }\end{array}$ & \\
\hline 588.995 & 589 & 0.001 \\
589.592 & & 0.10 \\
\hline \hline
\end{tabular}

\section{Conclusions}

In this work, we presented the experimental verification of a low-cost attachment for a commercial cell phone that allows to convert a mobile device into a low cost visible light spectrometer that can be used in educational applications.

Although the resolution of this spectrometer does not permit the identification of the sodium doublet, the resulting peak wavelength measurement coincides with the position of the doublet, which indicates that the instrument can reliably determine a wavelength of a visible light source.

The results obtained with PhysiscsSensor Mobile Edition show that it is possible to carry out quality measures in laboratories by using a simple instrumentation and adequate software, thus allowing the consolidation of knowledge given in theoretical classes.

In addition, the implementation of this methodology facilitates the collection of experimental data, allowing students to concentrate on the analysis of the physical phenomena and gives them the possibility to verify and discuss their results during the practice.

\section{Acknowledgements}

We would like to thank the School of Physics, Universidad Nacional de Colombia - Sede Medellin, for providing equipment, financial support and the opportunity to collect information about the device use and implementation in other educational institutions through some college teachers who are masters students of the "Maestría en Enseñanza de las Ciencias, Exactas y Naturales" program at the same university.

Portions of this work were presented at the IX Reunión Ibero-Americana de Óptica (RIAO) y del XII Encuentro Latino-Americano de Óptica, Láseres y sus Aplicaciones (OPTILAS) in PS2_09, 2016. 